\title{
The New Reform of Human Resource Management in the Era of Mobile Internet
}

\section{Hongmei Xie}

\author{
Institute of Information Technology of GuiLin University of Electronic Technology, Guiln, \\ Guangxi, 541004, China
}

Key words: human resource management; opportunities and challenges; reform; mobile Internet Abstract: Modern enterprise human resources management is an important support for the development of enterprises, with the development of the Internet and the era of big data, modern enterprise human resources management is also facing new opportunities and challenges. With the arrival of the mobile Internet era, the modern enterprise human resources management should take active countermeasures and management technology change, change the paper from the perspective of the transformation of management thought, management, change management functions, change the organization reform, management strategy, management mode reform and other aspects are discussed and analyzed.

\section{Introduction}

"Internet plus" action plan is committed to promoting the mobile Internet, cloud computing, big data, networking and modern manufacturing industry combination, to promote e-commerce, the Internet industry and the healthy development of Internet banking, Internet guide enterprises to expand the international market.Big data refers to the conventional software tools in the affordable range of time capture, management and processing of data collection, is the need for new treatment mode to have a stronger decision-making \& insight discovery and process optimization capabilities of massive, high rates of growth and diversification of information assets ${ }^{[1-3]}$. At present, the large data involved in a very wide range of disciplines, and the study of business management is less, the study of human resources management in modern enterprises is relatively scarce. Therefore, the research of "Internet plus" and big data integration in the mode and mechanism of modern enterprise human resources management, has an important significance for the enterprise's survival and innovation.

The rapid development of the network has a profound impact on human resources and its management. Faced with this challenge, the enterprise human resources management must carry on the omni-directional transformation, which can win the competitive advantage. The development of the network will have a significant impact on the concept, demand and status of human resources. It has expanded the scope of enterprise human resources, promote the change of concept of human resources in enterprises, enhance the autonomy of enterprise human resource work, promote the new pursuit of enterprise human resources, to further enhance the importance of enterprise human resources, demand of enterprise human resources increasingly high quality. Because of the above effects of network on human resources, it will lead to huge and profound changes in human resource management ${ }^{[4-5]}$. It will promote the essence of enterprise human resource management change, accelerate the management function transformation from administrative management to strategic human resource management, promote the management role of re positioning, improve the technological content of enterprise human resources management, causes the enterprise organizational structure change, encourage enterprises to attach importance to human resource management.

\section{The opportunity and challenge of human resource management in Network Era}

The main tasks of human resource management include recruitment, compensation and benefits, performance management, job design, training and development, manpower planning and employee communication, as shown in figure 1. 


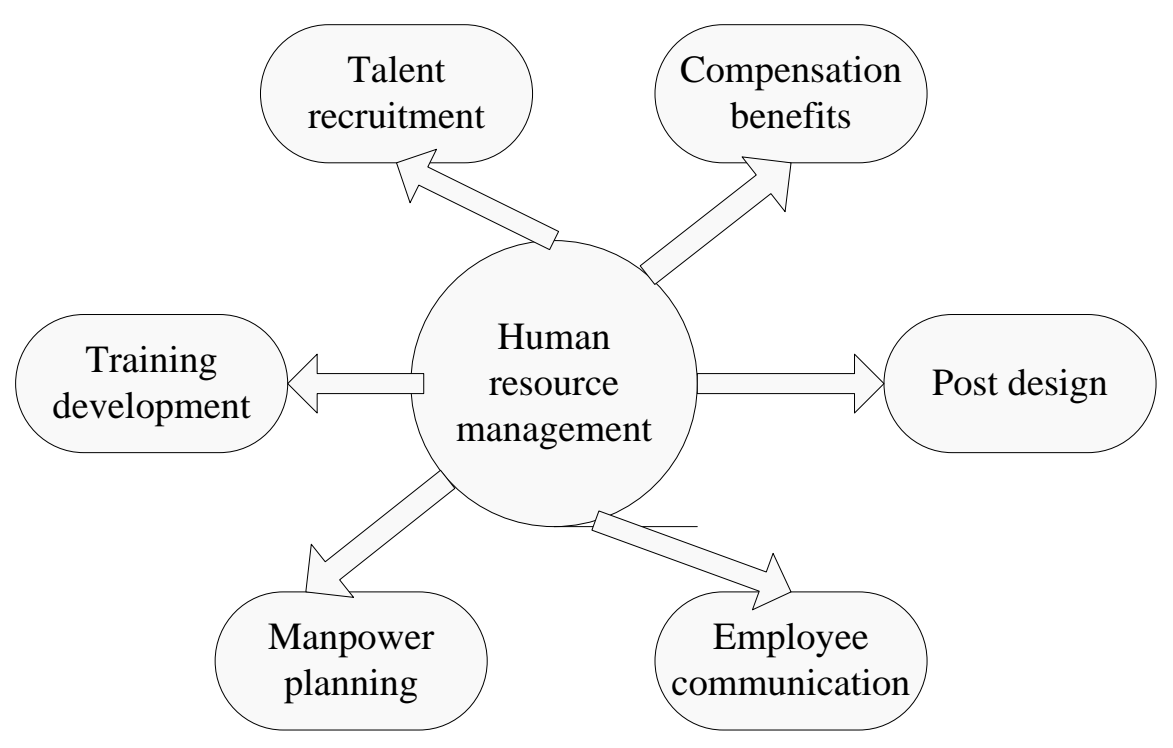

Fig.1 The main work of human resource management

\subsection{Opportunity analysis}

Network recruitment is becoming more and more important. For the recruitment, from simple posters, newspapers, magazines, advertising, a variety of recruitment, until today's online recruitment, change fast, dizzying. According to statistics, more than $40 \%$ of job recruitment in China is carried out through the Internet, 98\%.'s modern enterprises to accept the form of network recruitment. Online recruitment is not only fast and effective, but also save money.

The network makes the human resources information highly sharing. Through the human resources network (such as China talent network, China Talent Hotline, etc.), we can understand the current development of human resources in China and foreign countries, the latest trends and trends. Through the campus network (such as the major colleges and universities campus network, college students employment network, etc.), we can understand the information of Chinese and foreign famous university graduates, to help us recruit college graduates. Through the company's internal network, you can publish the latest news of human resources ${ }^{[6-7]}$. For example, the company issued a job vacancy, the staff according to their own expertise, ability to choose the position within the company for the rational deployment of the full use of existing human resources to create conditions.

Network makes human resource management play a greater role. Our system is placed in the folder before, the staff only to the human resources department to borrow. Today, the company can be published on the company's rules and regulations, employees can always read and feedback their views, to enhance the awareness of staff participation and compliance with the rules and regulations of the company's consciousness. At the same time, we use the company's network to conduct employee satisfaction survey and organize the staff to provide reasonable suggestions to stimulate the staff's sense of responsibility and enthusiasm. You can also set up an online university, called on employees to learn professional knowledge and basic skills on the Internet, to meet the staff's desire for knowledge.

\subsection{Challenge analysis}

The Internet has accelerated competition for talent. The market competition is the product competition, and the product competition is the competition of talents. Because of this, we all want to get talent, so that their own enterprises in the competition in an invincible position. The network has accelerated the competition for talent. Because the network has brought us so many opportunities, it has other ways to compete for talent unparalleled superiority. With the advent of the era of mobile Internet big data, competition for talent will be more intense, we only give full play to the advantages of the network in order to obtain talent ${ }^{[8]}$. 
The Internet is a threat to the stability of talents. The network has accelerated the competition of talents, and the network has threatened the stability of talents. As a high-tech enterprise, we need the talent in the market in short supply, we are the backbone of the search company to find the target, which gives us a lot of pressure to retain talent. In order to stabilize the team, is studying the occupation career planning, the planning aim is to make every employee to become their own development master, in consideration of the enterprise development at the same time, pay more attention to the development of their own employees, help employees develop their potential and rapid growth. Let employees choose a satisfactory job, your career detains them; improve the company's personnel management system, improve staff welfare, let the system and retain their treatment; create a good working environment, interpersonal environment, living environment, let the environment retain them; enhance the emotional communication and mental communication, let the feelings keep they.

Managers and the overall quality of human resources need to be improved. The network provides us with such a wide range of information, which is also a lot of false information, such as the applicant's resume is credible. Now there are media reports, most of the students are competing vice president, academic achievements are also a lot of water, online job resume received, the real situation is more. So, as a human resources manager, must improve their own quality, including basic language skills, computer operation, learning methods of human resource management, human resource development trends, enhance their own analysis and judgment ability. At the same time, due to the popularity of the network makes the flow of talent is too frequent, do not leave because someone and affect the normal production and operation of the company, we should pay more attention to the overall improvement of the quality of human resources, and strive to create knowledge and ability of the composite type compound a large number of people.

\section{The reform of enterprise human resource management in Network Era}

In order to adapt to the development of the network, the enterprise human resources management should actively take countermeasures, from the following 7 aspects, as shown in figure2.

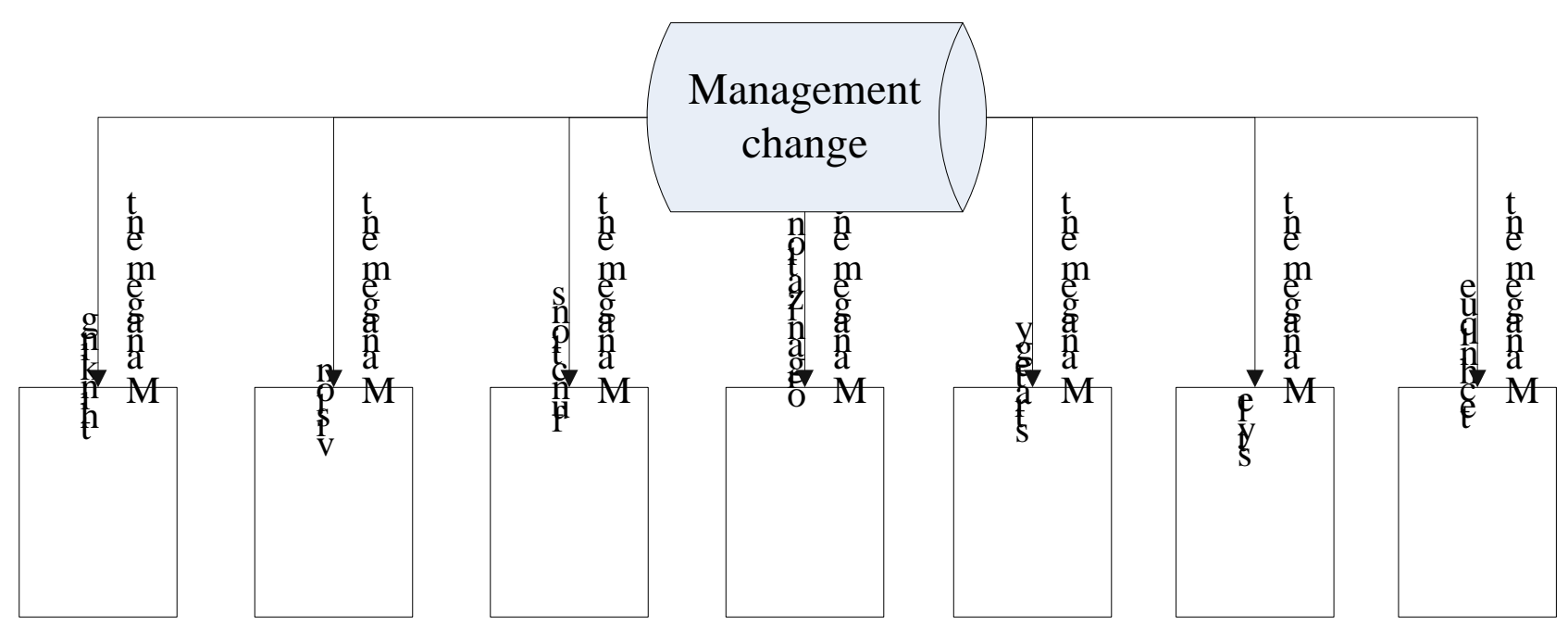

Fig.2 The reform of human resource management in Network Era

(1) Transformation of human resource management thinking

The change of human resource management thinking lies in speed. The biggest impact of the Internet on human society is speed, including the speed of contact, the speed of transactions, the speed of operation. A few minutes of news can be spread throughout the world, the capital flow between countries can be completed in an instant, technology, product life significantly shortened...... Speed became the first law of this era. Whether it is the development of human resources strategic planning, implementation, or the introduction of new tactical skills, whether it is to attract talent, retain the introduction of talent measures, or the concept of employment, education and practice. 
Which leading enterprises other enterprises half step, which the enterprise will win the victory of competition, and the enterprise which in action will be slightly slower, passive, or even be eliminated. Therefore, the human resource managers must develop the agile thinking, speed up the speed of thinking, the speed of information transmission, the speed of action, in order to respond to changes in the external environment.

\section{(2) Reform of human resource management}

The change of human resource management is the combination of globalization and localization. The development and application of the Internet will make economic activities through the network easily across borders, the constraints of space factors to a minimum. The scope of competition will be extended to the global market. In order to win in the competition, enterprises must be more concerned about and study the international human resource market rules and dynamic optimal allocation of human resources in the global scope, focus on staff training and competition ability of global sensitive sense of smell. On the other hand, some companies may set up branches in many parts of the world, and the social, political, economic, and cultural differences are different. Most of these companies only branch employees are local people, can quickly integrate into the local and local social identity, if hired most outsiders, takes a long time to familiar with the local situation, will make a deal with problems resistance increased, more difficult, and the cost is very high. Therefore, multinational companies from the global perspective to select local staff, local staff training skills.

(3) The change of human resource management function

The change of human resource management function lies in outsourcing and paying attention to the growth of employees. As mentioned earlier, the development of the Internet has led to the rise of human resources management from the tactical Department of the enterprise to the strategic sector. To highlight the strategic, strategic projects must be time to focus on human resource management, reduction of tactical investment projects, the objective requirements of some stable, non core, business outsourcing. At the same time, the ultimate carrier of any kind of core competence is the staff. Therefore, the core competence has nothing to do with little or no business outsourcing, focusing on the core competence of casting closely related to business management, especially the growth of employees, it is necessary. The network provides the possibility to optimize the allocation of resources worldwide, thus improving efficiency, from the perspective of optimizing the allocation of resources, enterprises can make their own good project human resource management should be strengthened, not good at project outsourcing.

(4) The change of human resource management organization

The change of human resource management organization lies in the cross functional team. With the development of the network, the knowledge, ability and experience of the employees are more important than ever before. Competitive pressure forces enterprises to reduce the cost of human resources, the rapid changes in the environment requires more flexible human resources organization. As a result, calls for the emergence of cross functional teams.

\section{(5) The change of human resource management strategy}

The change of human resource management strategy lies in employer brand strategy. The development of the network makes the global talent competition appeared intense degree of hitherto unknown, also appeared in the worldwide shortage of technology, the backbone of the business, to attract and retain qualified employees will become the strategic goal of the enterprise human resources management. To shape the employer brand, we must first fully understand the meaning of the enterprise product (service) brand, to ensure that the employer brand with it. Second, there must be a commitment from top management. This commitment includes the following content: the infusion represents a best employer behavior and attitude; work every day meaningful; unique enterprise culture; employee caring environment; to help employees grow.

(6) Reform of human resource management 
The change of human resource management is communication, trust and coordination. The traditional mode of human resource management is strict supervision and control. Information technology makes it possible for employees and managers, employees and employees to communicate with each other. It is urgent to change the mode of human resource management, pay attention to communication with employees, give employees a sense of trust, the implementation of self-management, flexible management will be adopted by most enterprises. What a business needs is a coordinator, not a manager.

(7) The change of human resource management technology

The change of human resource management technology lies in the extensive use of computer and network. The traditional human resource management technology is based on paper and pen, the main body is the telephone, telex and typewriter. In the age of the Internet, the computer and its network are the main tools of the society, so that employees and managers have never been connected with each other. In this way, the top management of the company can do to release information to all employees, employees also enjoy unprecedented exchange of information. At the same time, the network enables employees to work together at any time, anywhere.

\section{Summary}

The global network and information technology has brought an unprecedented revolution to the human information communication mode, which has caused the change of the information environment all over the world. The network technology enables people to ignore the differences of time and space, country, organization and culture, transmit, exchange and share all kinds of information resources in real time. Network, as one of the carriers of information, has the characteristics of high sharing of information resources, easy access, large number, fast update, affecting people's lives, work, but also affect the entire era. Human resource management considers that people are the most valuable resources, the purpose of which is to develop, find, develop and stabilize the human resources that we have or will have, and to serve the purpose of the company. Similarly, the network has also brought a lot of rare opportunities for human resources management, severe challenges and the reform of mobile Internet data.

\section{References}

[1] Nankervis A R, Cooke F L, Chatterjee S R, et al. New models of human resource management in China and India[M]. Routledge, 2013.

[2] Bratton J, Gold J. Human resource management: theory and practice[M]. Palgrave Macmillan, 2012.

[3] Stork C, Calandro E, Gillwald A. Internet going mobile: internet access and use in 11 African countries[J]. info, 2013, 15(5): 34-51.

[4] Cascio W F. Leveraging employer branding, performance management and human resource development to enhance employee retention[J]. 2014.

[5] Slovensky R, Ross W H. Should human resource managers use social media to screen job applicants? Managerial and legal issues in the USA[J]. info, 2012, 14(1): 55-69.

[6] Stredwick J. An introduction to human resource management[M]. Routledge, 2013.

[7] Lengnick-Hall M L, Lengnick-Hall C A, Rigsbee C M. Strategic human resource management and supply chain orientation[J]. Human Resource Management Review, 2013, 23(4): 366-377.

[8] Stone D L, Deadrick D L. Challenges and opportunities affecting the future of human resource management[J]. Human Resource Management Review, 2015, 25(2): 139-145. 